DOI 10.5216/ia.v45i3.65147

\title{
A RELAÇÃO DAS CARACTERÍSTICAS E DAS PRÁTICAS FAMILIARES COM OS COMPORTAMENTOS ESCOLARES DE ESTUDANTES DO ENSINO FUNDAMENTAL'
}

\author{
MARCELO Rodrigues CONCEIÇÃo \\ Universidade Federal de Alfenas (UNIFAL-MG), Alfenas, Minas, Gerais, Brasil \\ Paula Caroline de Andrade AleXandre \\ Secretaria de Educação de Minas Gerais (SEE-MG), Minas Gerais, Brasil
}

\begin{abstract}
Resumo: Por meio de uma investigação em uma escola pública de Minas Gerias, com estudantes do $6^{\circ}$ ano do ensino fundamental e seus familiares, buscou-se analisar a relação entre as condições objetivas de vida, as práticas familiares e o comportamento dos estudantes. Foram realizadas observações em sala de aula e entrevistas, por meio das quais se levantaram informações sobre: comportamento dos estudantes, composição familiar, grau de escolaridade, ocupação profissional, acompanhamento das atividades pedagógicas e convivência familiar. As análises foram desenvolvidas à luz da caracterização da forma escolar e da noção de habitus. Como conclusão, aponta-se a heterogeneidade do grupo, o que revela a possibilidade de que as diferentes condições de vida e de práticas socializadoras das famílias tenham influenciado as formas de comportamentos dos estudantes.
\end{abstract}

Palavras-chaves: Sociologia da Educação. Família. Escola. Socialização.

\section{INTRODUÇÃO}

Na Sociologia da Educação, um dos flancos de investigação se refere à influência das relações familiares e dos diversos aspectos que caracterizam suas condições socioeconômicas no desempenho escolar.

Pode-se perceber, de forma geral, duas perspectivas de abordagem desenvolvida ao longo dos anos. Num primeiro plano, as pesquisas analisaram a correlação entre o desempenho escolar e as condições econômicas e culturais das famílias. Estudos dos anos de 1960, de Bourdieu e Passeron (2008) e de Bourdieu (2012a, 2012b), direcionaram as investigações à organização do sistema de ensino francês, por meio de análises estatísticas entre as características das famílias, mais detidamente o grau de escolaridade e a ocupação das gerações antecessoras dos estudantes, além do percurso da escolarização. A principal conclusão foi de que havia baixa probabilidade de as classes populares ocuparem melhores posições sociais, como o ingresso no ensino superior, o que reforçaria o processo de reprodução das desigualdades sociais.

Nogueira (1998) aponta que houve, a partir dos anos de 1980, um deslocamento nos estudos em Sociologia da Educação, com o surgimento de análises 
sobre as interações entre família e escola. Passou-se a estudar as trajetórias dos estudantes e as estratégias das famílias voltadas aos processos de escolarização.

Lahire (1997) analisou as diferenças de resultados obtidos por estudantes das classes populares na França, nos anos de 1980, por meio das relações entre as configurações familiares e o espaço escolar, destacando a interdependência entre alguns fatores relacionados às famílias: as condições e disposições econômicas, as formas de cultura escrita, a ordem moral doméstica, as formas de exercício da autoridade e os modos de investimento pedagógico. Foi pesquisada a vida de estudantes da $2^{a}$ série do ensino elementar, crianças com cerca de oito anos de idade, para compreender quais as condições diferenciadas entre as famílias populares que possibilitariam escapar da probabilidade do fracasso escolar. O autor (1997) conclui que o sucesso escolar não tem relação direta com as práticas de investimento familiar, pois pode se dar mesmo na ausência de tal planejamento.

No Brasil, utilizando-se das discussões dessas duas perspectivas, destacam-se alguns trabalhos: Oliveira e Portes (2014); Paixão (2005); Portes (2006); Setton (2005); Viana (2012; 2012a); Zago (2000). Esses trabalhos apresentaram aspectos importantes sobre a organização familiar, a presença da família nos processos de escolarização e os sentidos e significados da escolarização para as classes populares e médias, mas não se direcionaram a analisar as formas de comportamento de estudantes na educação básica, em sua fase inicial. As análises se concentraram em trajetórias de estudantes que ingressaram no ensino superior, partindo da ideia de serem trajetórias de sucesso escolar.

Neste artigo ${ }^{2}$, discutem-se alguns dos aspectos que auxiliam a compreensão do comportamento de estudantes do ensino fundamental, de uma escola pública de Minas Gerais, localizada em um dos bairros mais afastados da zona urbana, de uma cidade de aproximadamente 80 mil habitantes. O objetivo foi analisar a relação entre as condições objetivas de vida, as práticas familiares e o comportamento dos estudantes.

Inicialmente, foram realizadas observações das relações no ambiente escolar, duramente três meses, em uma turma do $6^{\circ}$ ano do ensino fundamental. Foi por meio da constatação da presença de diferentes tipos de comportamento entre os estudantes que surgiu a questão central: haveria influência das características familiares e de sua forma de vida no comportamento dos estudantes? Dessa maneira, posteriormente, foram realizadas entrevistas com os familiares, em que se levantaram algumas características sobre as condições objetivas de vida e as práticas cotidianas de socialização das famílias, como: composição familiar, grau de escolaridade, ocupação profissional, lembranças escolares, perspectivas de futuro, acompanhamento das atividades pedagógicas, relação com a escola e convivência familiar. Segundo Paixão (2005, p. 168), é importante compreender os aspectos que podem se "constituir em entraves à escolarização" de quaisquer grupos de estudantes, na busca por estratégias pedagógicas mais inclusivas.

Dois conceitos nortearam o desenvolvimento do trabalho. A noção de habitus, elaborada por Bourdieu (1983), que são disposições duráveis construídas ao longo das trajetórias de vida dos agentes, de acordo com as influências das condições objetivas e dos processos de socialização vivenciados pelos agentes, auxiliou na compreensão da 
CONCEIÇÃO, M. R.; ALEXANDRE, P. C. de A.

relação entre os comportamentos dos estudantes em dois momentos de sua socialização: o familiar e o escolar, mas, principalmente, nas interações entre esses dois momentos que passam a ser simultâneos quando da inserção na escola. Alguns outros autores, como Setton (2005), Portes (2006) e Oliveira e Portes (2014), que tomaram por base as análises de Bourdieu em relação ao habitus, apresentaram indicações que avançaram no entendimento de vários mecanismos que influenciam o comportamento de estudantes. Outros, como Lahire (1997, 2002) e Nogueira e Nogueira (2002), apresentaram críticas à forma de utilização do conceito, que também são levadas em consideração. De outra parte, a definição da constituição de uma forma escolar, apresentada por Vincent, Lahire e Thin (2001), indica como diversos aspectos, construídos ao longo da história dessa instituição, moldaram as ações e indicaram como estudantes deveriam se portar na escola. Nesse sentido, a utilização do conceito se deu para verificar as aproximações e distanciamentos dos comportamentos dos estudantes em relação às características da forma escolar e analisar como se relacionavam com a vida cotidiana deles.

\section{A FORMA ESCOLAR E AS REGRAS DAS RELAÇÕES NO ESPAÇO DA SALA DE AULA}

Por meio de um trabalho diário de observação, em uma turma que contava com 33 estudantes, no início do ano letivo, foram captados aspectos sobre o comportamento dos estudantes em face às regras da escola e às relações com os professores.

Conforme afirma Silva (2007, p. 98), a prática pedagógica inaugurada pela escola revela a existência de regras que regulam o comportamento dos atores escolares e criam uma série de comportamentos desviantes àquelas regras. Tais regras podem ser compreendidas como pertencentes à forma escolar.

Vincent, Lahire e Thin (2001, p. 37-38), por meio de uma análise socio-histórica da relação entre a instituição escolar e as outras instituições, indicaram a emergência e a hegemonia de uma maneira de organizar a vida escolar e outras práticas. Nesse sentido, a forma escolar se baseou em um conjunto de aspectos como: determinação de um universo separado para a infância, definição de regras de aprendizagem, organização do tempo, multiplicação e repetição das atividades. A finalidade foi construir um modo de socialização específico, no caso o escolar. O sucesso dessa construção se disseminou para outras instâncias e processos de socialização, mas a predominância dessa forma se deve, também, às práticas socializadoras:

\footnotetext{
O modo escolar de socialização pode ser dito dominante não somente porque a forma escolar está largamente difundida nas diversas instâncias socializadora, mas também (e estes dois aspectos estão associados) porque a relação com a infância que ele implica, o tipo de práticas socializadoras que ele supõe, são os únicos a serem considerados como legítimos (VINCENT, LAHIRE, THIN, 2001, p. 42)
}

O levantamento feito nas observações se baseou nas regras gerais da escola e na convivência em sala de aula, em que foram identificadas diversas características da forma escolar, como a definição de regras de aprendizagem, a organização do tempo e a multiplicação e repetição das atividades pedagógicas. 
Um documento contendo as regras gerais da escola destacava: início das aulas às 13 horas e encerramento às 17:25h, sendo que os alunos que chegassem após esse horário deveriam justificar o atraso com a orientadora educacional, antes de ir para a sala; a escola não se responsabilizaria por objetos alheios ao ambiente escolar, tais como: dinheiro, joias, brinquedos, roupas, celulares; as crianças que recebessem bolsa família deveriam ter no mínimo $85 \%$ de frequência no mês para não terem o benefício cortado; não seria permitido o uso de celulares, estiletes e de aparelhos eletrônicos; o estudante deveria, preferencialmente, se vestir com o uniforme, a camiseta, da escola; seria proibido o uso de short e minissaia.

Várias dessas regras não eram cumpridas. Apesar de algumas delas se relacionarem ao ambiente externo à sala de aula, afetavam diretamente o trabalho pedagógico. Diariamente, os atrasos na entrada da primeira aula, na volta, após o horário do recreio, e as saídas não autorizadas das salas entre a troca dos professores costumavam atingir a organização de toda a escola, dado o volume de estudantes envolvidos. Nessas condições, a equipe diretiva da escola realizou várias estratégias para inibir a circulação dos estudantes entre os horários de aula e após o horário do recreio. Uma delas era a solicitação de que os estudantes fossem para as salas de aula, efetuada no pátio por professores e membros da equipe diretiva.

Dentro da sala de aula, havia duas maneiras de lidar com o comportamento dos estudantes, por parte dos professores, em relação aos diálogos. Quando os questionamentos versavam sobre os conteúdos, eram aprovados quase que instantaneamente, por meio de incentivos e elogios. Já quando eram aspectos que não se tratavam do objeto da aula, os diálogos eram reprovados imediatamente. Em várias situações, a comunicação desvinculada ao tema da aula estava associada a uma perturbação do trabalho pedagógico que muitas vezes interrompia o planejamento didático e atrapalhava a comunicação dirigida pelo professor, atuando, também, segundo Silva (2007, p. 113), "como uma espécie de base ou trampolim para os comportamentos mais graves". Vincent, Lahire e Thin (2001, p. 37-38) destacaram que as perguntas efetuadas em sala de aula deveriam apresentar as seguintes características, visando limitar a interação entre professores e estudantes: serem curtas e evidentes, apresentarem sentido completo e que suas respostas fossem passíveis de compreensão tomando por base o nível dos médios e não dos mais ou dos menos capazes.

O trabalho de observação evidenciou a existência de diferentes tipos de comportamentos dos estudantes, baseado nas regras gerais da escola e na concepção de forma escolar. Dessa forma, do mesmo modo que Silva (2007, p. 169) efetuou para analisar os aspectos da indisciplina, realizou-se uma tipologia entre a diferença dos comportamentos, conforme apresentado no quadro a seguir. Com isso, foi possível classificar os estudantes em diferentes grupos de comportamentos: habituados, desabituados e oscilantes entre os outros dois. Tal separação permitiu verificar as características das famílias de maneira a compará-las e entender melhor as diferenças e aproximações entre a vida familiar e o comportamento escolar. 
CONCEIÇÃO, M. R.i ALEXANDRE, P. C. de A

Quadro 1 - Classificação dos comportamentos em relação às regras observadas

\begin{tabular}{|c|c|c|}
\hline Grupo de regras & Desabituados & Habituados \\
\hline \multirow{3}{*}{$\begin{array}{l}\text { Comunicação e } \\
\text { mobilidade na sala de } \\
\text { aula }\end{array}$} & Conversar sobre coisas alheias à aula & $\begin{array}{l}\text { Dialogar sobre o conteúdo } \\
\text { da aula }\end{array}$ \\
\hline & Desrespeitar colegas e professores & $\begin{array}{l}\text { Tratar de forma respeitosa } \\
\text { colegas e professores }\end{array}$ \\
\hline & $\begin{array}{l}\text { Fazer barulhos inconvenientes durante a } \\
\text { aula: cantar, falar palavrão, gritar }\end{array}$ & $\begin{array}{c}\text { Mostrar interesse através } \\
\text { de perguntas relacionadas } \\
\text { ao conteúdo da aula }\end{array}$ \\
\hline \multirow{3}{*}{$\begin{array}{c}\text { Horários e organização } \\
\text { do espaço de sala de } \\
\text { aula }\end{array}$} & Atrasar durante a entrada da aula & Ser pontual na entrada \\
\hline & $\begin{array}{l}\text { Matar a aula / sair da sala de aula / } \\
\text { deslocar-se na sala de aula }\end{array}$ & $\begin{array}{l}\text { Sair da sala ou se deslocar } \\
\text { somente com autorização }\end{array}$ \\
\hline & $\begin{array}{c}\text { Desobedecer aos pedidos dos } \\
\text { professores }\end{array}$ & $\begin{array}{c}\text { Obedecer aos pedidos dos } \\
\text { professores }\end{array}$ \\
\hline \multirow{3}{*}{$\begin{array}{l}\text { Atividades } \\
\text { pedagógicas }\end{array}$} & $\begin{array}{l}\text { Não realizar as atividades pedagógicas } \\
\text { propostas }\end{array}$ & $\begin{array}{c}\text { Realizar as atividades no } \\
\text { tempo solicitado pelos } \\
\text { professores }\end{array}$ \\
\hline & $\begin{array}{c}\text { Perturbar os colegas interessados em } \\
\text { realizar as atividades }\end{array}$ & $\begin{array}{c}\text { Auxiliar os colegas com } \\
\text { dificuldades a realizar as } \\
\text { atividades }\end{array}$ \\
\hline & $\begin{array}{c}\text { Desviar a atenção para coisas alheias } \\
\text { durante as atividades }\end{array}$ & Estar atento ao professor \\
\hline
\end{tabular}

Fonte: Elaborado pelos autores (2020).

O comportamento de parte dos estudantes relacionado à falta de participação nas atividades escolares, ao desprezo pelo conteúdo pedagógico, presente nas aulas de todas as disciplinas, era impulsionado pela distração com os objetos alheios à aula: uso de telefone celular, uso de ioiô, trocas de bilhetes, brincadeiras com tubinhos de caneta entre outros. Essas práticas devem ser consideradas em relação às suas formas de vida e muito também em função do momento pelo qual os estudantes estavam passando, um novo modelo de convivência escolar e de socialização, praticado a partir do $6^{\circ}$ ano. Os diferentes grupos de comportamentos observados não podem ser tomados de forma isolada, uma vez que as atitudes dos estudantes fazem referência a um conjunto de valores trazidos das relações familiares, relacionados às condições e às práticas de suas vidas, e que podem ser organizados pelas ações socializadoras vivenciadas além do contexto da sala de aula. Revelam um habitus trazido da socialização familiar.

\section{O HABITUSE A RELAÇÃO FAMÍLIA-ESCOLA}

O habitusfunciona, de acordo com Bourdieu (1983, p. 65), "como um sistema de disposições duráveis e transponíveis que, integrando todas as experiências passadas, funciona a cada momento como uma matriz de percepções, de apreciações e de ações". São princípios geradores e estruturadores das práticas e das ações dos sujeitos. Dessa forma, segundo Bourdieu (1983, p. 61), as práticas produzidas pelo habitus são determinadas, simultaneamente, pelo futuro, por meio de um plano ou projeto de atuação, e pelo passado, pois seu princípio de produção tende a reproduzir as estruturas objetivas das quais seriam o produto. 
Bourdeiu (1983, p. 74) enfatiza que a interiorização das estruturas objetivas leva, dentro dos grupos, a processos de construção de um sentido objetivo, unitário e sistemático, que deixam de lado as intenções subjetivas e os projetos conscientes. Nem todos os membros da classe terão as mesmas experiências, porém terão maiores oportunidades de estar à mercê das situações vivenciadas pela classe à qual pertence. A análise se direcionou a verificar como alguns elementos da constituição e das ações familiares podem explicar tipos de comportamentos diferentes dos estudantes.

Segundo Bourdieu e Passeron (2008, p. 64), a primeira educação, geralmente familiar, por meio de um trabalho pedagógico, "produz um hábito primário, característico de um grupo ou uma classe" e está na base de organização de qualquer outro hábito posterior, como o escolar. Nesse sentido, o habitus familiar se constitui em importante mecanismo de transmissão de práticas e valores:

Na realidade, cada família transmite a seus filhos, mais por vias indiretas que diretas, um certo capital cultural e um certo ethos, sistema de valores implícitos e profundamente interiorizados, que contribui para definir, entre outras coisas, as atitudes face ao capital cultural e à instituição escolar. A herança cultural, que difere, sob dois aspectos, segundo as classes sociais, é a responsável pela diferença inicial das crianças diante da experiência escolar e, consequentemente, pelas taxas de êxito (BOURDIEU, 2012a p. 4142).

A combinação entre o ethos e o capital cultural, segundo Boudieu (2012a, p. 50), definiria as condutas e atitudes na escola, fazendo com que as crianças das classes populares tivessem que se desdobrar para alcançar êxito em sua escolarização. Portanto, tratar do habitus familiar e sua relação com as práticas escolares é fundamental para compreender as ações dos estudantes.

Duas críticas podem ser consideradas importantes em relação ao habitus. Lahire (1995) chamou a atenção para a necessidade de se estudar a dinâmica interna das famílias, pois a transmissão do habitus e de práticas dos adultos para os estudantes não é algo mecânico, hereditário, como teria sugerido Bourdieu. Nogueira e Nogueira (2002, p. 27), nesse sentido, apontam que os processos de formação e transmissão do habitus não podem ser efetuados de maneira automática, pois dependeriam de trabalho ativo realizado por pais e filhos, além de outros membros em contato prolongado e efetivamente significativo. De outra parte, para Nogueira e Nogueira (2002, p. 27), o conceito de habitus, pensado no meio familiar e na formação individual, não pode ser deduzido, como teria feito Bourdieu (1983), diretamente do que seria seu habitus de classe, pois não se reduzem à posição de classe, tendo disposições gerais de compartilhamento de hábitos/disposições, mas que cada família, cada indivíduo seria "produto de múltiplas e, contraditórias influências sociais".

Levando em consideração os questionamentos acerca da forma como teria sido deduzida o habitus, ainda assim se considera importante verificar como as condições de existência e as práticas familiares podem influenciar nas formas de comportamento de estudantes em processo de escolarização, mesmo sabendo que o trabalho não efetuou 
as indicações necessárias de aprofundamento investigativo e analítico, para se afirmar que houve a transmissão de um habitus. Após apresentar as etapas e os conceitos que permitiram o desenvolvimento das etapas iniciais, a formulação da questão central, mais precisamente, se deu da seguinte maneira: quais são as características da vida das famílias que podem conformar ou influenciar o comportamento dos estudantes, derivado de um habitus primário, que possibilitou classificá-los em grupos diferentes, conforme as aproximações e os distanciamentos em relação aos aspectos definidos pelo conceito de forma escolar?

Parte-se, para tanto, além da influência das condições objetivas, da conclusão de Oliveira e Portes (2014, p. 1149-50) de que as práticas desenvolvidas no ambiente familiar são importantes para a construção de um habitus escolar que pode auxiliar no acesso e na permanência de estudantes de camadas populares no ensino superior, o habitus escolar seria definido como disposições em relação à escola e às atividades escolares que teriam alta probabilidade de sustentarem a longevidade escolar. Dentre alguns elementos, referentes à vida familiar, os autores (2014, p. 1150) destacam a "presença de uma "ordem moral doméstica", a ética do trabalho, a respeitabilidade, a valorização do "trabalho escolar" da família e a "solidariedade familiar".

\section{AS CONDIÇÕES E AS PRÁTICAS FAMILIARES}

A seleção das famílias dos grupos de estudantes entrevistadas se baseou na regularidade dos tipos de comportamentos manifestados em sala de aula e sua relação com as regras escolares, divididos em três segmentos: os habituados, caracterizados por participarem constantemente da rede de comunicação e de aprendizagem dirigida pelo professor; os desabituados, que manifestavam comportamentos opostos ao do segmento anterior, que a escola tende a repreender; e os intermediários, que agiam oscilando entre as características dos outros dois segmentos, principalmente pelo fato de que participavam de eventos que visavam a impedir o desenvolvimento das atividades pedagógicas e concentravam maior número de estudantes.

Quadro 2 - Famílias entrevistadas

\begin{tabular}{|c|c|c|}
\hline Habituados & Intermediários & Desabituados \\
\hline Bryan & Kelyson & Uriel \\
\hline Melissa & Marina & Alice \\
\hline Leonel & Henrique & Gisela \\
\hline
\end{tabular}

Fonte: Elaborado pelos autores (2020).

Os nomes indicados no quadro acima são fictícios para se preservar a identidade dos estudantes. Havia na sala de aula observada, de acordo com a classificação proposta, oito estudantes habituados, 13 intermediários e 12 desabituados. Esperava-se realizar ao menos cinco entrevistas em cada grupo, mas as dificuldades em encontrar a moradia das famílias, nem sempre com endereços atualizados e algumas recusas, tornaram possível ter como base empírica três famílias por grupo.

As três famílias entrevistadas do grupo dos denominados habituados eram biparentais, com dois filhos cada. Responderam à pesquisa duas mães, uma com $5^{\circ}$ ano do ensino fundamental e a outra com ensino médio completo, e um pai com ensino médio completo e com cursos técnicos em mecânica. Em todas as casas, as duas figuras 
parentais trabalhavam e exerciam as seguintes funções: doméstica/ajudante geral; manicure/mecânico de manutenção; auxiliar administrativo/tapeceiro. Houve indicações de conversas acerca da futura profissão dos filhos e da importância dos estudos para se concretizar tal intento. No que se refere às relações entre pais e filhos, as cobranças sobre o desempenho escolar foram citadas como frequentes, realizadas por meio de questionamentos e conversas sobre o andamento das atividades na escola. Em duas famílias, ocorria o auxílio para a realização das atividades escolares, caso dos responsáveis com maior grau de escolaridade.

Todas as famílias desse grupo se mostraram satisfeitas com o desempenho de seus filhos na escola e citaram comparecer às reuniões rotineiras, além das conversas, reclamações e cobranças sobre a atuação dos professores.

Sobre a memória do tempo de escola, os entrevistados destacaram ter boa lembrança, sustentada por alguns acontecimentos específicos como as aulas de matemática e as feiras de Geografia e História, além dos jogos escolares.

As conversas entre os familiares pareceram ser diárias e indicaram certa proximidade e afeto, apesar de todos dividirem seus tempos entre o trabalho e o lar:

Pai de Bryan: "Nós somos muito brincalhões, nós contamos muita piada, nós rimos. Eu cobro muito dele, sou muito chato na hora que preciso ser. Saímos juntos, eu procuro ser um pai bem presente. Eu não sei se ele gosta, parece que sim. Em casa assim, a gente joga bola e se eu vou no supermercado ele vai comigo".

Na família em que a mãe tinha grau de escolarização inferior ao das outras famílias, além de não conseguir desempenhar um forte acompanhamento das tarefas escolares, o estudante desenvolvia atividades extraescolares, frequentava o Cáritas, que é uma associação beneficente que promove projetos de leitura para crianças, aulas de reforço e de teatro, oficinas de artesanato e de música, jogos de basquete e de capoeira. $\mathrm{Na}$ associação, os meninos encontravam a possibilidade de contatos com aspectos da forma escolar, o que pode ter contribuído para uma aproximação com os aspectos lá valorizados, permitindo sua inserção nesse grupo. Dentre as atividades, citou jogar basquete e fazer capoeira.

Duas mães e uma irmã responderam à pesquisa no grupo dos intermediários. $\mathrm{A}$ irmã, de 22 anos, cursou até o $1^{\circ}$ ano do ensino médio, era casada e não morava na casa, mas cuidava do estudante, pois a mãe tinha um problema de saúde. As famílias eram compostas por poucos membros nas residências: uma por cinco, uma por quatro e a outra por três, sempre formadas por pais e filhos. O grau de escolaridade parental estava concentrado no ensino fundamental, duas mães realizaram o ensino fundamental, uma não concluiu e, no outro caso, o pai possuía o ensino médio completo e havia iniciado seus estudos em nível superior. Em uma das residências, os dois responsáveis trabalhavam; em outra, a esposa estava desempregada; e, na última, a mãe passava por problemas de saúde e fazia um tratamento no Centro de Apoio Psicossocial (Caps). As atividades exercidas eram: atendente supermercado/motorista de empresa; desempregada/operador de máquinas; vigilante/incapaz. 
CONCEIÇÃO, M. R.; ALEXANDRE, P. C. de A.

As perspectivas para o futuro passavam por aspectos mais gerais como "tem que estudar" e o "pai pega no pé":

\begin{abstract}
Irmã de Henrique: "[...] ele vai querer fazer uma faculdade, porque agora meu pai está fazendo uma faculdade. Então agora meu pai que está incentivando. E ele fala "não, eu quero jogar bola e não quero estudar não. Não vejo a hora de parar de estudar para jogar bola". E meu pai fica pegando no pé dele. "É bom, ele é um menino desobediente, mas é um menino bom".
\end{abstract}

Nesse grupo, os familiares entrevistados não relataram lembranças do tempo escolar, pois indicaram ser um passado distante. Em relação ao dia a dia no ambiente familiar, os pais afirmaram que o cotidiano é muito corrido, o que os afastavam de muitas conversas com os filhos, mas que, mesmo assim, questionavam o que aprenderam na escola. Um estudante foi citado pela família como alguém que não gostava de conversar, mas que, quando necessário, apresentava seus problemas.

O auxílio na realização das tarefas escolares foi pouco citado. Em apenas uma família, a de escolarização mais alta do grupo, ocorria o apoio por parte do pai.

A avaliação da escolarização dos filhos apresentou perspectivas diferentes para os casos pesquisados: melhorou em dois casos e foi muito fraco em outro. Segundo os relatos, a presença dos familiares na escola se restringia às reuniões e às convocações específicas, o que era algo raro.

Um estudante desse grupo também realizava atividades no Cáritas e revelou uma aproximação com a lógica escolar, no que se refere aos horários e responsabilidades com as atividades escolares. A mãe de Kevin citou que o filho tinha uma vida "bem reclusa", pois se restringia à escola, ao Cáritas, à igreja e à residência, onde ajudava a executar as tarefas de casa e cuidar do irmão e limitadas à televisão e ao celular.

Três mães foram entrevistadas no grupo dos desabituados. Em nenhuma das famílias, a respondente ou o cônjuge completaram o ensino fundamental. Apenas uma das mães concluiu os anos iniciais desse nível. As famílias eram distintas na sua composição: uma com 10 membros, sendo composta pelos pais, sete filhos e o avô; e os demais lares eram compostos pelos pais e três e dois filhos, respectivamente. No que se referia à ocupação parental, eram: do lar/lavrador; doméstica/desempregado; ajudante geral/lavrador.

Em relação às perspectivas de futuro, percebeu-se maior distanciamento de objetivos mais concretos. Pensavam em um futuro melhor, mas indicaram que os filhos tinham dificuldades para entender:

Mãe de Uriel: "Converso. Ele gosta muito de esporte, gosta de jogar bola. Estudo mesmo ele não gosta não, mas agora está até mudando de escola porque lá embaixo estava meio impossível de estudar. Aí está mudando de escola para ver se melhora alguma coisa". 
As lembranças da escola eram marcadas por aspectos de desilusão, como o abandono para trabalhar na roça, problemas de saúde ou dificuldades financeiras vivenciadas. O distanciamento nas relações com os filhos foi explicitado em todas as entrevistas, sendo relacionado à intensidade da ocupação desempenhada pelos responsáveis, o que impactava no tempo disponível para conversas com os filhos.

Destaca-se que, mais do que no segmento dos intermediários em que houve um caso, apareceram como importantes os auxílios dos estudantes nas tarefas domésticas, mais destacados por parte das duas mães de meninas:

\begin{abstract}
Mãe de Gisela: "Ela me ajuda muito em casa, sabe arrumar a casa. Sabe fazer de tudo, o que for para fazer ela faz. Trabalhadeira e me ajuda muito também. Elas todas são. Elas são sossegadas, vão à Igreja, à Congregação Cristã do Brasil. Vai para a escola e vem embora.".
\end{abstract}

A presença das famílias na escola foi destacada somente quando ocorriam reuniões ou por convocações extraordinárias. Nesse grupo, não houve uma avaliação mais precisa sobre a satisfação com a vida escolar dos filhos, mas deram a entender que os filhos apresentavam dificuldades de aprendizagem e de comportamento: um não ligava para os estudos, outro citava ser melhor estudante em relação aos anos anteriores porque a escola era mais fraca e um, apesar de ir bem, a mãe frisou que ele não queria estudar.

Os responsáveis afirmaram não auxiliar na realização das tarefas escolares, porque, segundo eles, não tinham condições e conhecimento para tal. Uma mãe afirmou que o estudante não levava caderno para casa e as demais indicaram não saber resolver as tarefas propostas.

As condições objetivas e as práticas de vida das famílias, que compõem a socialização familiar, indicaram ter sido adquirido, interiorizado um habitus primário que é responsável, em boa parte, pelas formas como os estudantes se comportam na escola. Ele também influencia as possibilidades de transformação desse habitus, quando confrontado com os anseios da forma escolar, em outro momento de socialização, às vezes, como no caso dos desabituados, muitos distantes das práticas vivenciadas até então.

\title{
DIFERENTES CONDIÇÕES DE VIDA E PRÁTICAS SOCIALZIADORAS
}

Ao analisar as condições de vida e as formas de convivência apontadas pelas famílias é possível elencar os elementos que determinam ou indicam possibilidades de influenciarem os comportamentos apresentados pelos estudantes, tomando por norteadores a definição de forma escolar e da noção de habitus.

As características e as práticas de vida das famílias pesquisadas indicaram certa correspondência direta entre as exigências de comportamento da escola e os aspectos de escolaridade, ocupação e composição familiar. Apesar de parecerem tênues as diferenças entre as características, nota-se que exerciam grande influência. Os habituados eram aqueles em que os pais têm maior escolaridade, exercem ocupações 
no comércio e nos serviços e as famílias são compostas por quatro pessoas. No polo contrário, os pais dos desabituados apresentam grau de escolaridade de, no máximo, ensino fundamental e exercem atividades na agricultura e no plano doméstico. Além disso, havia a presença de mais pessoas na moradia.

Tal indicação não necessariamente significa que haja a transposição das características socioeconômicas, de forma mecânica, mas chama a atenção que, quando se analisam as práticas familiares que valorizam a forma escolar, a influência dessas condições parece ser mais bem fundamentada. É nas famílias dos habituados, mesmo naquela em que havia escolaridade próxima da dos desabituados, que se encontravam as ações mais próximas dos requisitados pela forma escolar: acompanhamento dos filhos, auxílio nas tarefas. Também é nesse grupo que ocorria maior interação entre os familiares, em que conversas e brincadeiras eram acompanhadas por conselhos, perspectivas e discussões sobre o futuro e a importância da escola. No polo contrário, dos desabituados, a vida se mostra muito mais difícil e há, em virtude de necessidades econômicas e de falta de conhecimento da vida e do conteúdo escolar, maior distanciamento dessas práticas.

Destacam-se, dessa maneira, dois pontos: a aproximação de parte das classes populares com a forma escolar e o distanciamento quase total dessas práticas por outra parte. Essa segmentação pode ser fruto das diferentes condições objetivas que afetam também as práticas em relação à escola. O exercício da ocupação profissional (local, rede de relações, horários, tipo de esforço) parece ser um elemento central nessa diferença, pois efetua uma espécie de ligação entre as condições objetivas, as práticas socializadoras realizadas na convivência familiar e as oportunidades possibilitadas por ele, o que pode levar à percepção de diferentes expectativas em relação à escolarização e ao futuro.

O fato de trabalharem em atividades que envolvem o convívio com pessoas de diferentes profissões e situações sociais, possibilitava, para algumas famílias, especialmente do grupo dos habituados, a percepção de outros espaços e circunstâncias de socialização, além de outra visão sobre as disputas por melhores posições sociais, que indicavam aos pais a necessidade de maior acompanhamento e cobrança em relação ao desempenho escolar dos filhos. No polo contrário, dos desabituados, as famílias eram mais numerosas e exerciam ocupações mais desgastantes, as práticas e os comportamentos estavam mais distantes dos esperados pela lógica escolar do que as famílias dos outros dois grupos. No grupo intermediário, houve indícios do que os fazem transitar entre as duas outras categorias. As famílias apresentavam oscilações no nível de escolarização entre o nível fundamental e médio e exerciam ocupações que transitam entre os trabalhos manuais e atividades relacionadas ao contato mais abrangente com outras pessoas e classes sociais.

Vincent, Lahire e Thin (2001, p. 39-40) indicam que são numerosos os traços da forma escolar encontrados nas práticas socializadoras das famílias, como o aumento das atividades extraescolares, voltadas à ocupação do tempo livre, aquisição de saberes específicos, o disciplinamento, caracterizado pelo respeito às regras, e o gosto pelos estudos e práticas corporais muito relacionadas ao esporte, que indicam as preocupações com os elementos estabelecidos na forma escolar, como a organização do tempo e o disciplinamento. Entretanto, essas práticas condizem mais com as classes superiores e médias. Para as classes populares, principalmente as que estariam mais 
dominadas no plano cultural, os autores destacam que há um distanciamento em relação ao modo escolar de socialização. As atividades extraescolares para esse segmento teriam uma função mais ligada a tirar as crianças da rua e preservar a influência familiar. Tais atividades só estiveram presentes nos grupos dos habituados e dos intermediários, que revelaram a organização de uma ordem doméstica que se parece com algumas regras escolares. Nesses grupos, o maior tempo de convivência e maior conhecimento sobre as atividades escolares, possíveis pelo nível de instrução e pela socialização realizadas em outros espaços, aproximavam os estudantes de um direcionamento ao habitus escolar. $\mathrm{O}$ exemplo do grupo dos intermediários revela essa indicação: um estudante passou a ser melhor acompanhado pelo pai que ingressara no ensino superior, e um estudante que exercia atividades extraescolares tornou-se mais próximo ao idealizado no sistema de ensino. Outro estudante frequentava atividades extraescolares em uma associação. Tais aspectos indicam uma aproximação com as características da forma escolar.

Nos desabituados, o distanciamento em relação à forma escolar foi revelado. Ao mesmo tempo em que conta que a filha é muito lenta nos estudos e que não pode auxilia-la nas tarefas escolares, por não possuir muito "entendimento", uma mãe manifestou expectativas que estão para além da escola, caso da necessidade de trabalhar, algo tão presente nessa classe social, e que revela a dicotomia estudo e trabalho como distanciamento das possibilidades escolares, para os mais desfavorecidos.

Para se analisar a construção de um habitus escolar, próximo às indicações de forma escolar, há que se considerar que as condições objetivas influenciam as práticas socializadoras e o inverso é verdadeiro, criando expectativas de futuro, baseadas nas possibilidades do presente, que podem transformar ou manter o habitus primário que é o familiar.

De modo geral, a comparação entre as diferentes práticas das famílias entrevistadas parece indicar a correspondência entre as esperanças subjetivas e as condições de existência do grupo familiar, conforme acentuam as proposições de Bourdieu (2012a, p. 46-49), de que as expectativas em relação ao futuro encontram-se sempre ajustadas às condições objetivas, medidas pela distribuição dos diferentes tipos de capitais, de modo a excluir a possibilidade de desejar algo improvável. Nessas expectativas, há que se atentar para os apontamentos de Lahire (1997) sobre as causas do improvável, no que se refere ao sucesso escolar das classes populares, que se direcionariam a aspectos adquiridos e valorizados nas práticas familiares, por suas relações sociais e pelo envolvimento com uma forma de vida pautada numa ordem moral doméstica e não diretamente à escolarização em si, que podem modificar a situação analisada aqui, pois o habitus estaria em processo de transformação, pela ação da forma escolar. Setton (2005, p. 79) chama atenção para as condições diferenciadas de aquisição de uma cultura escolar, indicada por Bourdieu (2012a). Seriam dois tipos de aprendizado distintos. Um primeiro, precoce e insensível, efetuado no ambiente familiar desde a primeira infância e que pode, ou não, ser prolongado por meio do aprendizado. O outro seria um aprendizado "tardio, metódico, adquirido fora da família, nas 
CONCEIÇÃO, M. R.; ALEXANDRE, P. C. de A.

instituições de ensino ou em outras esferas informais da educação" (SETTON, 2005, p. 79). O último estaria em processo para o grupo pesquisado.

As expectativas das famílias entrevistadas revelaram perspectivas marcadas pela situação em que se encontravam. As famílias de Melissa e Bryan, mais escolarizadas, produziam práticas mais favoráveis à vida escolar dos filhos. Afirmaram conversar sobre a profissão a ser seguida pelos filhos e sobre a importância dos estudos para atingir tal intento. Realizavam um maior acompanhamento e auxílio nas atividades didáticopedagógicas, que só Ihes era possível graças às informações, aos saberes e às práticas escolares acumulados em sua trajetória escolar, na convivência social em outras instituições e no trabalho. E, do mesmo modo, Henrique, do grupo intermediário, passou a encontrar em casa, desde a entrada de seu pai na universidade, uma ação efetiva e facilitadora de adequação às exigências escolares, visando um futuro melhor. No caso das mães de Uriel e Gisela, do grupo dos desabituados, as necessidades materiais e o desconhecimento da lógica escolar não indicavam práticas voltadas à introdução e/ou incorporação dos aspectos da forma escolar.

\section{CONSIDERAÇÕES FINAIS}

O grupo social pesquisado não indicou homogeneidade de características e de práticas socializadoras. Muito pelo contrário. Já no trabalho de observação, revelou-se a presença na sala de aula tanto de práticas mais conformes à forma escolar legítima quanto de práticas consideradas pela instituição escolar como inadequadas. Nas características e práticas diferenciadas das famílias, foi possível constatar a heterogeneidade do grupo, o que nos leva à aceitação dos questionamentos acerca da forma de construção do habitus, efetuadas por Nogueira e Nogueira (2002, p. 26), centrada no conceito de classe social. Devido às variações das constituições do habitus nos grupos sociais, ele não teria sido suficiente para explicar a diferenciação entre os grupos familiares, segundo suas práticas escolares, pois as atitudes tomadas em relação à educação dos filhos variariam mais em função de autonomia e de autoridade do que de classes. Ao se direcionar o olhar para os segmentos dentro do grupo pesquisado e relacionar suas condições objetivas e suas práticas socializadoras, parece sim haver uma relação estreita entre tais características e o comportamento escolar. Nesse sentido, seria indicado atentar para a construção de habitus diferentes na mesma classe social, configurados por processos de socialização que envolveriam várias práticas. $O$ próprio Bourdieu (2015) aponta diferenças nos gostos e estilos de vidas de ocupações socioprofissionais da mesma classe social. Um habitus de classe clivado por práticas diversas em relação à posição que os agentes, nesse caso, as famílias, ocupavam.

As melhores condições objetivas, composição familiar, escolaridade e ocupação, podem ter auxiliado na obtenção de informações sobre a forma escolar e o modo de funcionamento do sistema de ensino. Também, como indicam Lahire (1997) e Portes (2006), o modo de vida mais próximo à caracterização da forma escolar aproxima os estudantes dos aspectos desejados por ela, sem, necessariamente, se ter a intenção direta de atingir o sucesso escolar, mas servir para a vida. Algumas ações, que caracterizam tal aspecto, são: assistir os trabalhos escolares, esforçar para compreender e apoiar, permitir a participação de outros na vida do filho e na orientação das práticas familiares relacionadas à educação. Havia, no grupo dos habituados e em um caso dos 
intermediários, um conjunto de práticas favoráveis à educação escolar dos filhos, como contato com a universidade e cursos profissionalizantes, trabalho regular que propiciava maior convívio com pessoas de diferentes posições sociais que permitiam, pelo menos, vislumbrar perspectivas de futuro e de possibilidades de ascensão social, um acompanhamento efetivo e auxílio nas tarefas escolares. Nesse sentido, concorda-se com Setton (2005, p. 79), pois existem, também, fatores extraescolares que influenciam no desempenho e no aproveitamento escolar que auxiliam no acesso aos bens da cultura, que indicam variação no comportamento e no rendimento dos estudantes.

Em síntese, as diferenças e semelhanças entre as características e as formas de vida das famílias entrevistadas auxiliam a pensar na possibilidade de que as formas de comportamento e as práticas escolares dos estudantes estejam relacionadas às condições objetivas de vida e às práticas socializadoras, influenciadas por mecanismos entrecruzados de relações sociais, como as efetuadas no exercício das atividades profissionais, na convivência familiar e em outros espaços de socialização. Tais diferenciações interferem diretamente nas expectativas de escolarização e de visão de futuro, pensadas por familiares e estudantes, o que influencia o modo de se comportar na escola.

THE RELATIONSHIP OF FAMILY CHARACTERISTICS AND PRACTICES WITH THE SCHOOL BEHAVIORS OF ELEMENTARY SCHOOL STUDENTS

ABSTRACT: Through an investigation at a public school in Minas Gerias, with students from the 6th grade of elementary school and their families, we sought to analyze the relationship between objective living conditions and family practices in students' behavior. It was classroom observations and interviews were conducted, in which information was gathered about: student behavior, family composition, degree of schooling, professional occupation, monitoring of of pedagogical activities and family interaction. The analyses were developed in the light of the characterization of the school form and the notion of habitus. One conclude, the heterogeneity of the group is pointed out, which reveals the possibility the different living conditions and socializing practices of families influenced the forms of behavior of students.

KEYWORDS: Sociology of Education. Family. School. Social Practices and Conditions.

LA RELACIÓN DE LAS CARACTERÍSTICAS Y PRÁCTICAS FAMILIARES CON EL COMPORTAMIENTO ESCOLAR LOS ALUMNOS DE LA EDUCACION BASICA 
CONCEIÇÃO, M. R.; ALEXANDRE, P. C. de A.

RESUMEN: Por una investigación en una escuela pública de Minas Gerais, con alumnos de $6^{\circ}$ año de primaria y sus familias, se buscó analizar la relación entre condiciones objetivas de vida, las prácticas familiares y el comportamiento de los alumnos. Se realizaron observaciones en el aula y entrevistas a familiares, en las que se recogió información sobre: comportamiento del alumno, composición familiar, nivel educativo, ocupación profesional, seguimiento de las actividades pedagógicas y vida familiar. Los análisis se desarrollaron a la luz de la caracterización de la forma escolar y la noción de habitus. Como conclusión, se señala la heterogeneidad del grupo, que revela la posibilidad de que las diferentes condiciones de vida y prácticas de socialización de las familias influyó en las formas de comportamiento de los alumnos.

PALABRAS CLAVE: Sociología de la Educación. La Familia. La Escuela. Socialización.

NOTAS

${ }^{1}$ Nossos agradecimentos ao apoio concedido pela Coordenação de Aperfeiçoamento de Pessoal de Nível Superior (Capes) e pela Fundação de Amparo à Pesquisa do Estado de Minas Gerais (Fapemig), para a realização da pesquisa.

${ }^{2} O$ presente trabalho é fruto de parte de uma pesquisa desenvolvida ao longo de três anos, com o objetivo de analisar o impacto das estatísticas escolares, mais especificamente dos resultados do Índice de Desenvolvimento da Educação Básica (Ideb), nas práticas cotidianas da escola.

REFERÊNCIAS BIBLIOGRÁFICAS

BOURDIEU, P. A distinção: crítica social do julgamento. Porto Alegre: Zouk, 2015.

BOURDIEU, P. A escola conservadora: as desigualdades frente à escola e à cultura. In: NOGUEIRA, M. A.; CATANI, A. (orgs.). Escritos de educação. 13a ed. Petrópolis: Vozes, 2012a, p. 39-64.

BOURDIEU, P. Futuro de classe e causalidade do provável. In: NOGUEIRA, M. A.; CATANI, A. (orgs.). Escritos de educação. 13a ed. Petrópolis: Vozes, 2012a, p. 81-126.

BOURDIEU, P. PASSERON, J-C. A reprodução: elementos para uma teoria do sistema de ensino. Petrópolis: Vozes, 2008.

BOURDIEU, P. Esboço de uma Teoria da Prática. In: ORTIZ, Renato (org.). Pierre Bourdieu: sociologia. São Paulo: Ática, 1983, p. 46-81.

LAHIRE, B. Sucesso escolar nos meios populares: as razões do improvável. São Paulo: Ática, 1997. 
LAHIRE, B. Reprodução ou prolongamentos críticos? Educação \& Sociedade, Campinas, ano XXIII, n. 78, p. 37-55, abr. 2002. Disponível em: https://www.scielo.br/pdf/es/v23n78/a04v2378.pdf. Acesso em: 10 fev. 2020.

NOGUEIRA, M. A. Relação família-escola: novo objeto na Sociologia da Educação. Paidéia, Ribeirão Preto, n. 15, p. 91-103, fev./ago. 1998. Disponível em: http://www.revistas.usp.br/paideia/article/view/46525/50282. Acesso em: 4 jun. 2014.

NOGUEIRA, C. M. M.; NOGUEIRA, M. A. A sociologia da educação de Pierre Bourdieu: limites e contribuições. Educação \& Sociedade, Campinas, ano XXIII, n. 78, p. 15-36, abr. 2002.

OLIVEIRA, L. F.; PORTES, É. A. Ascensão e distanciamento na trajetória social, escolar e profissional de um jovem das camadas populares. Perspectiva, Florianópolis, v. 32, n. 3, p. 1145 - 1164, set./dez. 2014.

PAIXÃO, Léa. Significado da escolarização para um grupo de catadoras de um lixão. Cadernos de Pesquisa, São Paulo, v. 35, n. 124, p. 141-170, jan./abr. 2005.

PORTES, É. A. Algumas dimensões culturais da trajetória de estudantes pobres no ensino superior público: o caso da UFMG. Revista Brasileira de Estudos Pedagógicos, Brasília, v. 87 , n. 216, p. 220-235, maio/ago. 2006.

SETTON, M. G. J. Um novo capital cultural: pré-disposições e disposições à cultura informal nos segmentos com baixa escolaridade. Educação \& Sociedade, Campinas, v. 26, n. 90, p. 77-105, jan./abr. 2005.

SILVA, L. C. Disciplina e indisciplina na aula: uma perspectiva sociológica. 2007. 285f. Tese (Doutorado em Educação) - Faculdade de Educação, Universidade Federal de Minas Gerais, Belo Horizonte, 2007.

THIN, D. Para uma análise das relações entre famílias populares e escola: confrontação entre lógicas socializadoras. Revista Brasileira de Educação, Rio de Janeiro, v. 11, p. 211-225, 2006. Disponível em: http://www.redalyc.org/articulo.oa?id=27503202. Acesso em: 04 abr. 2015.

VIANA, M. J. Longevidade escolar em famílias de camadas populares: algumas condições de possibilidade. 2012. 264f. Tese (Doutorado em Educação) - Faculdade de Educação, Universidade Federal de Minas Gerais, Belo Horizonte, 2012.

VIANA, M. J. Práticas socializadoras em famílias populares e a longevidade escolar dos filhos. Educação em Revista, Belo Horizonte, v.28, n.01, p.421-440, mar. 2012a. 
CONCEIÇÃO, M. R.; ALEXANDRE, P. C. de A.

VINCENT, G.; LAHIRE, B.; THIN, D. Sobre a história e a teoria da forma escolar. Educação em Revista, Belo Horizonte, n. 33, p. 7-47, jun. 2001.

ZAGO, N. Quando os dados contrariam as previsões estatísticas: Os casos de êxito escolar nas camadas socialmente desfavorecidas. Paidéia, Ribeirão Preto, v. 10, n. 18, p. 70-80, jan./jul. 2000.

Marcelo Rodrigues Concelção: Professor associado da Universidade Federal de Alfenas (Unifal-MG). Leciona as disciplinas de sociologia e metodologias de pesquisa. É graduado em Ciências Sociais (Bacharelado e Licenciatura) pela Universidade São Marcos; mestre e doutor em Educação: História, Política, Sociedade, pela Pontifícia Universidade Católica de São Paulo (PUC/SP).

Orcid: https://orcid.org/0000-0003-0277-749X

E-mail:marcelo.conceicao@unifal-ms.edu.br

Paula Caroline de Andrade AleXandre: Graduada em Ciências Sociais (Bacharelado e Licenciatura) pela Universidade Federal de Alfenas. Atualmente é professora regente de Sociologia na rede estadual de Minas Gerais.

Orcid: https://orcid.org/0000-0002-7404-2305

Email: p.carolineandrade@gmail.com

Este periódico utiliza a licença Creative Commons Attribution 3.0, para periódicos de acesso aberto (Open Archives Iniciative - OAI). 